\title{
Early versus Delayed Laparoscopic Cholecystectomy in Acute Calcular Cholecystitis According to Tokyo Guidelines: A Prospective Study
}

\author{
YEHIA H. ZAYED, M.D.; ASHRAF I. AL-SHARKAWY, M.D. and MO'MEN I. ALI AL-MINYAWI, M.Sc. \\ The Department of General Surgery, Faculty of Medicine (for Girls), Al-Azhar University, Cairo
}

\begin{abstract}
Background: Acute Cholecystitis (AC) is acute inflammation of the gallbladder wall associated with leukocytosis and fever and is the second most common cause of inflammatory acute abdomen. The Tokyo Guidelines 2013 (TG13) was started as a way to show recommended diagnosis and treatments according to the severity of AC. Patients are classified into Grade I (mild) acute cholecystitis in a healthy patient with no organ dysfunction, Grade II (moderate) acute cholecystitis is associated with (Elevated WBC count $>18,000 / \mathrm{mm}^{3}$, mass in the right upper abdominal quadrant, duration of complaints $>72$ hours, Grade III (severe) acute cholecystitis is associated with organ dysfunction.
\end{abstract}

Aim of Work: The aim of the work was to study TG13 in diagnosis and severity of acute cholecystitis.

Patients and Methods: This analytical prospective study was carried out on 50 patients presented with acute calcular cholecystitis admitted in the General Surgery Department at Al-Zahraa University Hospital in the period from April 2016 to November 2017 with assesmment and treatment according to TG13 either early or laparoscopic cholecystectomy.

Results: Statistical analysis of our study showed accuracy with TG13 and other studies done according to it with low conversion rate from laparoscopic to open surgery and low intraoperative and post-operative complications.

Conclusions: It is important to use Tokyo guidelines during diagnosis and treatment of acute calcular cholecystitis.

Key Words: Tokyo guideliness - Acute calcular cholecystitis - Laparoscopic cholecystectomy.

\section{Introduction}

ACUTE cholecystitis is defined as an acute inflammation of the gallbladder wall associated with leukocytosis and fever regardless of the cause. Acute cholecystitis is the second most common

Correspondence to: Dr. Yehia H. Zayed, The Department of General Surgery, Faculty of Medicine (for Girls), Al-Azhar University, Cairo cause of inflammatory acute abdomen. It encounters $3 \%$ to $9 \%$ of overall hospital admissions). About $60 \%$ of patients with acute cholecystitis are women, although, acute cholecystitis develops in men more frequently than would be expected because of the relative increased prevalence of gallstones in women, and cholecystitis tends to be more severe in men [1] . Since early 1990s, lap. cholecystectomy has become the standard treatment for patients with symptomatic cholecystolithiasis [2]. However, current literature suggests that the rate of intraoperative conversion from laparoscopic to open cholecystectomy is $1 \%-15 \%$, higher rates of conversion, up to $75 \%$, must be expected in patients with gangrenous cholecystitis or gallbladder empyema [3]. The most common intraoperative complications of laparoscopic surgery are related to needle and trocar insertion and bleeding. CBD injuries during LC remain the most serious complication encountered with this procedure. Reports have assessed that the rate of BDI has ascended from $0.2-0.4 \%$ for open cholecystectomy to $0.6-0.8 \%$ for LC [4] The complications encountered during early and delayed LC are numerous. Specific complications of LC are hemorrhage, gall bladder perforation, bile leakage, bile duct injury, and perihepatic collection, and others such as, wound sepsis, hematoma, foreign body inclusions and adhesions. One has to keep in mind that complication and mortality rates are significantly higher in older patients ( $>65$ years) and patients admitted to the hospital as emergencies and those with acute or

\footnotetext{
Abbreviations:

TG13 : Tokyo Guidelines 2013.

US : Ultrasonography.

AC : Acute Cholecystitis.

BDI : Bile Duct Injury.
} 
complicated cholecystitis (gangrene, empyema, perforation, etc.) [5]. There were no diagnostic criteria or severity assessment criteria for this common disease until 2007. In 2006, we conducted a systematic review and sponsored an international consensus conference in Tokyo, Japan. This meeting resulted in the development of the Tokyo Guidelines for the management of acute cholangitis and cholecystitis (TG07). These guidelines were the world's first guidelines to include diagnostic criteria and severity assessment of acute cholecystitis [6]. However, since its publication, we and others have found potential shortcomings in TG07 in clinical practice [7]. To update the Tokyo Guidelines for the management of acute cholangitis and cholecystitis, they organized the Tokyo Guidelines Revision Committee to evaluate TG07, recognize new evidence, and conduct a multi-center analysis to revise the guidelines (TG13). The Tokyo Guidelines Revision Committee concluded that the term "definite diagnosis" could not be supported in current practice without positive diagnostic imaging studies [8] Acute calculous cholecystitis is diagnosed radiologically by the concomitant presence of thickening of the gallbladder wall ( $5 \mathrm{~mm}$ or greater), pericholecystic fluid, or direct tenderness when the probe is pushed against the gallbladder (ultrasonographic Murphy's sign) [1]. In TG13 diagnostic criteria for acute cholecystitis or suspected diagnosis by One Local signs of inflammation (Murphy's sign, RUQ mass/pain/tenderness) + Systemic signs of inflammation (fever, elevated CRP, elevated WBC count) but definite diagnosis needs imaging findings characteristic of acute cholecystitis. According to severity, patients are classified into Grade I (mild) acute cholecystitis that can be defined as acute cholecystitis in a healthy patient with no organ dysfunction and mild inflammatory changes in the gallbladder, Grade II (moderate) acute cholecystitis is associated with any one of the following conditions (elevated WBC count $>18,000 / \mathrm{mm}^{\text {, }}$, Palpable tender mass in the right upper abdominal quadrant, duration of complaints $>72$ hours or marked local inflammation, Grade III (severe) acute cholecystitis is associated with dysfunction of any one of the following organs/ systems (cardiovascular dysfunction hypotension, neurological dysfunction, respiratory dysfunction, renal dysfunction, hepatic dysfunction or hematological dysfunction) [8]. The Tokyo Guidelines flowchart was started as a way to show recommended treatments according to the severity of AC. However, it did not cover issues like physical status such as co-morbidities (especially organ dysfunctions) or other predictive factors/risk factors when choosing a treatment pathway according to severity. In addition, until now Grade III acute cholecystitis was considered not suitable for straightforward laparoscopic cholecystectomy (LapC). In the TG18 guidelines, they proposed a modified flowchart based on recent recommendations in the clinical setting, particularly evidence reported after the publication of TG13. In the TG18 guidelines, we propose a modified flowchart based on recent recommendations in the clinical setting, particularly evidence reported after the publication of TG13 [9]. In Grade I: There are no substantial differences with the TG13 guidelines, but the flowchart does include additional considerations on patient risk factors. In principle, early Lap-C is the first-line treatment for the cases of Grade I. However, in patients with surgical risk (broken line) using Charlson comorbidity index (CCI) score and the American Society of Anesthesiologists physical status classification (ASA-PS) score, antibiotics and general supportive care are firstly necessary. Then, after improvement with initial medical treatment, they could be indicated to LapC. In Grade II (moderate) AC is often accompanied by severe local inflammation. Therefore, surgeons should take the difficulty of cholecystectomy into consideration in selecting a treatment method. Early Lap-C could be first indicated if advanced laparoscopic techniques are available. When the judgment of cholecystectomy is made, general condition should be evaluated using CCI and ASAPS. Elective cholecystectomy after the improvement of the acute inflammatory process could be indicated in the poor conditional patients. If a patient does not respond to initial medical treatment, urgent or early gallbladder drainage is required. If not, transfer to advanced center should be considered. In Grade III AC is accompanied by organ dysfunction. Appropriate organ support in addition to initial medical treatment is necessary. Early or urgent cholecystectomy can be possible under intensive care, when the judgment of cholecystectomy is made using predictive factor, CCI and ASA-PS. As early operation is best in those patients who have rapidly reversible failure of cardiovascular and/or renal failure, elective cholecystectomy may be performed after the improvement of acute illness has been achieved by gallbladder drainage. Lap-C in Grade III of AC should be performed by an expert surgeon who often completed additional training beyond their basic general surgical education under intensive care. If not, transfer to advanced center should be considered [9].

\section{Aim of work:}

The aim of the work was to study Tokyo guidelines in detecting severity of acute cholecystitis 
and also to evaluate the role of Tokyo guidelines in the optimal time of laparoscopic cholecystectomy either early or delayed in acute cholecystitis.

\section{Patients and Methods}

This analytical prospective study was carried out on 50 patients presented with acute calcular cholecystitis admitted in the General Surgery Department at Al-Zahraa University Hospital in the period from April 2016 to November 2017. The 50 patients were classified according to Tokyo guidelines (2013) into 3 groups regarding the severity of attack: Mild group: 28 patients $(56 \%)$ were presented with mild acute cholecystitis, they were healthy patient with Signs of acute cholecystitis (persistent pain $>6$ hours, fever, high WBC, positive Murphy's sign) and mild inflammatory changes of the gallbladder), moderate group: 13 patients $(26 \%)$ were presented with moderate acute cholecystitis with (persistent pain $>72$ hours, palpable mass in the right hypochondrium, positive Murphy's sign, WBC $>18.000 / \mathrm{mm}^{3}$ and marked gallbladder inflammation), severe group: 9 patients (18\%) were presented with severe acute cholecystitis with severe gallbladder inflammation e.g., and at least one of the following organ dysfunction: (Cardiovascular, pulmonary, renal, neurologic, hepatic or hematologic).

Inclusion criteria: All patients presented with acute calcular cholecystitis.

Exclusion criteria: Patients presented with any of absolute contraindication for laparoscopic cholecystectomy, patients who are unfit for general anaesthesia, perforated acute cholecystitis with generalized peritonitis, cholangitis or obstructive jaundice.

\section{All patients were subjected to:}

Informed consent was obtained for all patients and approved by local ethical committee.

Detailed history was taken including personal history (name, age, sex, marital state, residency, smoking, .........), complaint include (pain, fever, nausea, vomiting, .......... ) present history include analysis of patient complaint and other symptoms suggestive other system affection, past history of similar attack, recurrent biliary colic or other diseases, family history and history of previous operation or medication.

Examination was done for all patients include general examination (conscious level, pulse, blood pressure, temperature, respiratory rate, and heart rate, ), local abdominal examination with spe- cial attention to presence of tenderness, guarding, rigidity, palpable mass and positive Murphy's sign in right hypochondrium.

Investigation included: Laboratory investigation (CBC, liver function tests, renal function tests, alkaline phosphatase, RBS, CRP, ABG, amylase, lipase, L. Imaging study included (X-ray chest, ECG, abdominal ultrasonography, C.T. abdomen and MRCP if needed with diagnostic criteria like (thick wall of gall bladder, pericholecystic fluid, subserosal edema, impacted stone in Hartman's pouch and Intramural gas).

All patients were diagnosed with acute calcular cholecystitis according to Tokyo guidelines (TG13) by: One Local signs of inflammation (Murphy's sign, RUQ mass/pain/tenderness) + Systemic signs of inflammation (fever, elevated CRP, elevated WBC count) + imaging findings characteristic of acute cholecystitis. According to severity patients are classified into Grade I (mild) acute cholecystitis can be defined as acute cholecystitis in a healthy patient with no organ dysfunction and mild inflammatory changes in the gallbladder, Grade II (moderate) acute cholecystitis is associated with any one of the following conditions (Elevated WBC count $>18,000 / \mathrm{mm}$, Palpable tender mass in the right upper abdominal quadrant, duration of complaints $>72$ or marked local inflammation, Grade III (severe) acute cholecystitis is associated with dysfunction of any one of the following organs/ systems (cardiovascular dysfunction hypotension, neurological dysfunction, respiratory dysfunction, renal dysfunction, hepatic dysfunction or hematological dysfunction). According to Tokyo guidelines patients with mild and moderate attack were undergone early 4-port laparoscopic cholecystectomy while patients with severe attack were undergone conservative treatment for 48-72 hours on fluid, antibiotics, analgesics for interval 6-8 weeks, and prepared for late 4-port laparoscopic cholecystectomy. Failure of conservative treatment leaded to open cholecystectomy or cholecystostomy. Operative data that were assessed intra-operatively include any difficulty that faced the surgeon during the operation such as: (Difficult dissection, excessive adhesions, obscured anatomy, bleeding, bile duct injuries, bowel injury and operative time which was recorded from first port insertion to last port site closure). Post-operative management: All patients received good support from intravenous maintenance fluid, antibobiotis, analgesics and had warm oral liquids after the operation once there was normal bowel movement and no nausea nor vomiting. For two weeks postoperative patients were observed for: (Bleeding, jaundice, pain, bowel 
injury, bile leak, wound infection, signs of abdominal collection like pain, fever, tendeness, guarding and rigidity).

\section{Statistical analysis:}

The followings tests were used in statistical analysis:

1- Chi-square test for categorical variables, to compare between different groups.

2- Fisher's Exact or Monte Carlo correction correction for chi-square when more than $20 \%$ of the cells have expected count less than.

3 - Student $t$-test for normally distributed quantitative variables, to compare between two studied groups.

*: Statistically significant at $p \leq 0.05$.

\section{Results}

In the 50 patients with acute calcular cholecystitis, 28 patients $(56 \%)$ presented with mild attack, 13 patients $(26 \%)$ with moderate attack while 9 patients $(18 \%)$ with severe attack. $(71.5 \%, 61.5 \%$, $66.7 \%$ ) of patients in (mild, moderate and severe group) respectively were female mean age was $41.3 \pm 15.76$ years in mild group, $41 \pm 20.26$ years in moderate group and $46.44 \pm 7.57$ years in severe group. All patients (100\%) in our study presented with persistent right hypochondrial pain more than 6 hours, fever and leukocytosis. The duration of pain before hospital admission was between 6hours and 3 days in $100 \%$ of patients in the mild group but in only $15 \%$ of patients in the moderate group as the majority $(85 \%)$ in moderate group presented with pain more than 3 days also $100 \%$ of patients in severe group presented with persistent pain more than 3 days. $75 \%$ of patients in mild group presented TLC between 11.000 and $18.000,77 \%$ in moderate group and $100 \%$ in severe group present with TLC more than 18.000 . Also $100 \%$ of all patients had tendenness, guarding, positive Murph's sign in right hypochondrium and there was palpable right hypochondrial mass in only $28.5 \%$ in mild group, in $84.6 \%$ in moderate group and in $89 \%$ in severe group. In severe group $22.2 \%$ presented with hypotension, serum creatinine level was high more than 2 in $77.8 \%$, INR high above 1.5 in $33.3 \%$ and platelet count was low below 100.000 in $45.5 \%$. $100 \%$ of patients in our study presented with normal respiratory rate. $93 \%$ of mild group, $77 \%$ of moderate group and $89 \%$ of severe group were diagnosed by only U.S. C.T was needed in $15 \%$ of moderate group and $11 \%$ of severe group. MRCP was done in $7 \%$ of mild group and $8 \%$ of moderate group. All patients in mild and moderate group undergone early laparoscopic cholecystecyomy (Fig. 1). 2 patients (7\%) in mild group and 1 patient $(7.5 \%)$ in moderate group needed intraoperative conversion to open surgery (Figs. 2,3). All patients in severe group undergone conservative management which was successful in 6 patients $(67.7 \%)$ and they undergone late laparoscopic cholecystectomy and none of them needed conversion to open surgery but conservative treatment failed in 3 patients (33.3\%), 2 of them (22.2) undergone urgent open cholecystectomy and one of them (11.1\%) undergine urgent open cholecystostomy.

Table (1): Comparison between the two studied groups according to intraoperative course.

\begin{tabular}{|c|c|c|c|c|c|c|}
\hline & \multicolumn{2}{|c|}{$\begin{array}{l}\text { Early lap } \\
(n=38)\end{array}$} & \multicolumn{2}{|c|}{$\begin{array}{l}\text { Late lap } \\
\quad(\mathrm{n}=6)\end{array}$} & \multirow{2}{*}{$\begin{array}{l}\text { Test } \\
\text { of sig. }\end{array}$} & \multirow{2}{*}{$p$} \\
\hline & $\mathrm{N}$ & $\%$ & $\mathrm{~N}$ & $\%$ & & \\
\hline Bleeding & 5 & 13.2 & 1 & 16.7 & $\begin{array}{l}\chi^{2}= \\
0.054\end{array}$ & $\begin{array}{r}\mathrm{FE}_{p=} \\
1.000\end{array}$ \\
\hline CBD injury & 0 & 0.0 & 0 & 0.0 & & - \\
\hline Bowel injury & 0 & 0.0 & 0 & 0.0 & - & - \\
\hline \multicolumn{7}{|l|}{ Time (minutes): } \\
\hline $\begin{array}{l}\text { Min.-max. } \\
\text { Mean } \pm \text { SD. } \\
\text { Median }\end{array}$ & \multicolumn{2}{|c|}{$\begin{array}{l}35.0-75.0 \\
50.79 \pm 11.71\end{array}$} & \multicolumn{2}{|c|}{$\begin{array}{l}40.0-55.0 \\
49.166 \pm 5.84\end{array}$} & $t=0.850$ & 0.397 \\
\hline
\end{tabular}

Table (2): Comparison between the two studied groups according to post-operative follow-up.

\begin{tabular}{|c|c|c|c|c|c|c|}
\hline & \multicolumn{2}{|c|}{$\begin{array}{l}\text { Early lap } \\
(\mathrm{n}=38)\end{array}$} & \multicolumn{2}{|c|}{$\begin{array}{l}\text { Late lap } \\
\qquad(\mathrm{n}=6)\end{array}$} & \multirow{2}{*}{$\begin{array}{l}\text { Test } \\
\text { of sig. }\end{array}$} & \multirow{2}{*}{$p$} \\
\hline & $\mathrm{N}$ & $\%$ & $\mathrm{~N}$ & $\%$ & & \\
\hline \multicolumn{7}{|l|}{ Pain: } \\
\hline Mild & 31 & 81.6 & 5 & 83.3 & $\chi^{2}=$ & $\mathrm{FE}_{p=}$ \\
\hline Severe & 7 & 18.4 & 1 & 16.7 & 0.011 & 1.000 \\
\hline Bleeding & 0 & 0 & 0 & 0 & & - \\
\hline Jaundice & 0 & 0 & 0 & 0 & - & \\
\hline Bile leake & 1 & 2.6 & 0 & 0.0 & $\begin{array}{l}\chi^{2}= \\
0.162\end{array}$ & $\begin{array}{r}\mathrm{FE}_{p=} \\
1.000\end{array}$ \\
\hline Bowel injury & 0 & 0 & 0 & 0 & & \\
\hline Abdominal collection & 1 & 2.6 & 0 & 0 & $\begin{array}{l}\chi^{2}= \\
0.162\end{array}$ & $\begin{array}{r}\mathrm{FE}_{p=} \\
1.000\end{array}$ \\
\hline $\begin{array}{l}\text { Wound infection } \\
\text { Hospital stay (days): }\end{array}$ & 0 & 0.0 & 1 & 16.7 & $\begin{array}{l}\chi^{2}= \\
6.481\end{array}$ & $\begin{array}{l}\mathrm{FE}_{p=}= \\
0.136\end{array}$ \\
\hline Min.-max. & \multicolumn{2}{|c|}{$1.0-7.0$} & \multicolumn{2}{|c|}{$1.0-3.0$} & $t=$ & 0.509 \\
\hline Mean \pm SD. & \multicolumn{2}{|c|}{$1.36 \pm 1.05$} & \multicolumn{2}{|c|}{$1.66 \pm 0.81$} & 0.667 & \\
\hline Median & \multicolumn{2}{|l|}{1.0} & \multicolumn{2}{|l|}{1.5} & & \\
\hline \multicolumn{7}{|l|}{ Oral feeding (hrs): } \\
\hline Min.-max. & \multicolumn{2}{|c|}{$6.0-24.0$} & \multicolumn{2}{|c|}{$6.0-24.0$} & $t=$ & $0.041^{*}$ \\
\hline $\begin{array}{l}\text { Mean } \pm \text { SD. } \\
\text { Median }\end{array}$ & \multicolumn{2}{|c|}{$10.47 \pm 5.94$} & \multicolumn{2}{|c|}{$\begin{array}{l}16.33 \pm 8.61 \\
18.0\end{array}$} & $2.112^{*}$ & \\
\hline
\end{tabular}


Table (3): Comparison between the studied groups according to intraoperative course.

\begin{tabular}{|c|c|c|c|c|c|c|c|c|}
\hline & \multicolumn{2}{|c|}{$\begin{array}{l}\text { Conversion } \\
(\mathrm{n}=3)\end{array}$} & \multicolumn{2}{|c|}{$\begin{array}{l}\text { Open cholecystectomy } \\
\qquad(\mathrm{n}=2)\end{array}$} & \multicolumn{2}{|c|}{$\begin{array}{l}\text { Open cholecystectomy } \\
\qquad(\mathrm{n}=1)\end{array}$} & \multirow{2}{*}{$\begin{array}{l}\text { Test } \\
\text { of sig. }\end{array}$} & \multirow{2}{*}{$p$} \\
\hline & $\mathrm{N}$ & $\%$ & $\mathrm{~N}$ & $\%$ & $\mathrm{~N}$ & $\%$ & & \\
\hline Bleeding & 3 & 100.0 & 1 & 50.0 & 0 & 0.0 & $\begin{array}{l}\chi^{2}= \\
3.362\end{array}$ & $\begin{array}{l}\mathrm{MC}_{p}= \\
0.204\end{array}$ \\
\hline CBD injury & 0 & 0 & 0 & 0 & 0 & 0 & - & - \\
\hline Bowel injury & 0 & 0 & 0 & 0 & 0 & 0 & - & - \\
\hline $\begin{array}{l}\text { Time minutes: } \\
\text { Min.-max. } \\
\text { Mean } \pm \text { SD. } \\
\text { Median }\end{array}$ & $\begin{array}{l}80 \\
85 \\
85\end{array}$ & $\begin{array}{l}0-90.0 \\
\pm 5.0 \\
0.0\end{array}$ & $\begin{array}{l}70 \\
80 \\
80\end{array}$ & 14.14 & & & $\begin{array}{l}t= \\
0.600\end{array}$ & 0.591 \\
\hline
\end{tabular}

Table (4): Comparison between the studied groups according to post-operative course.

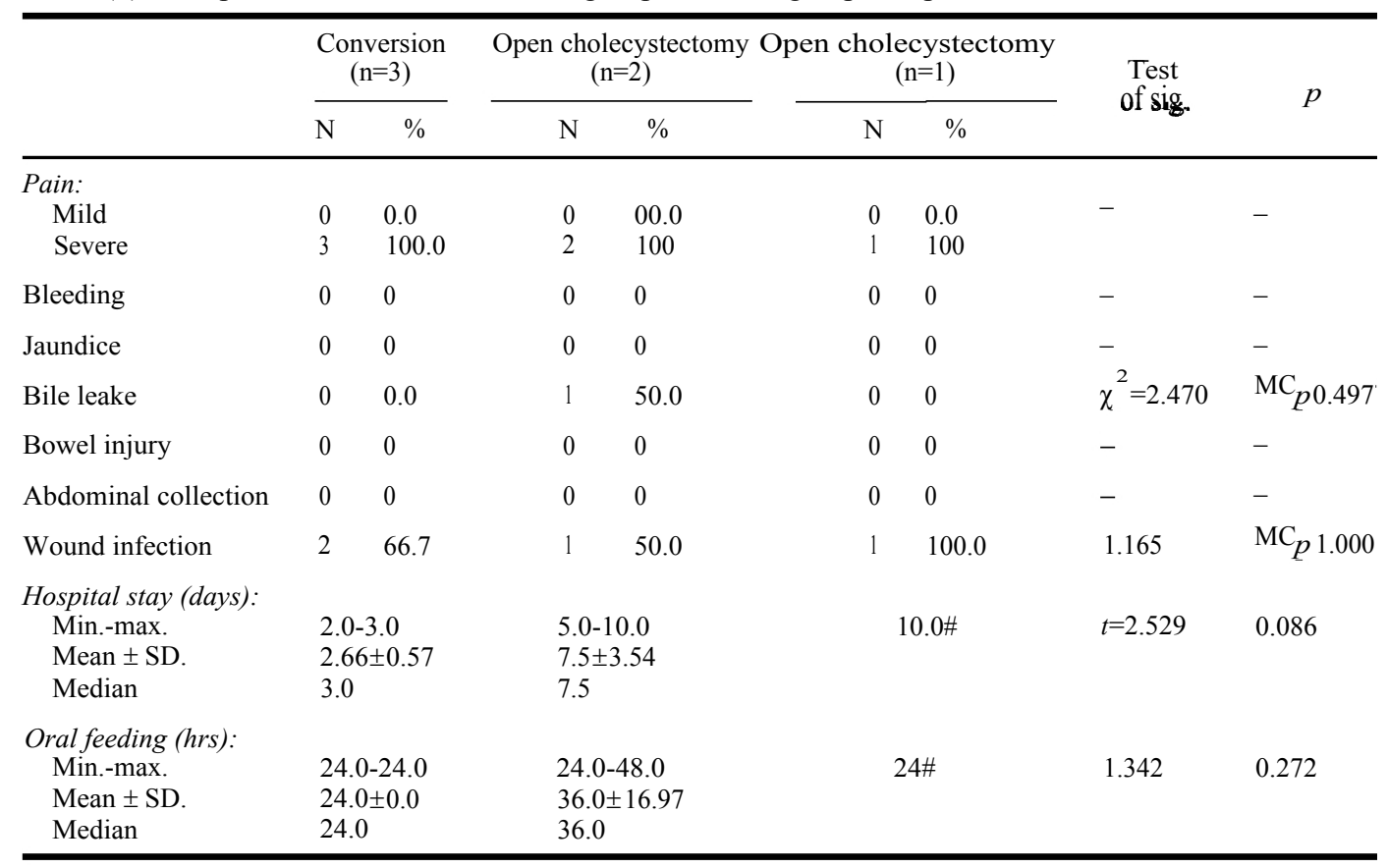

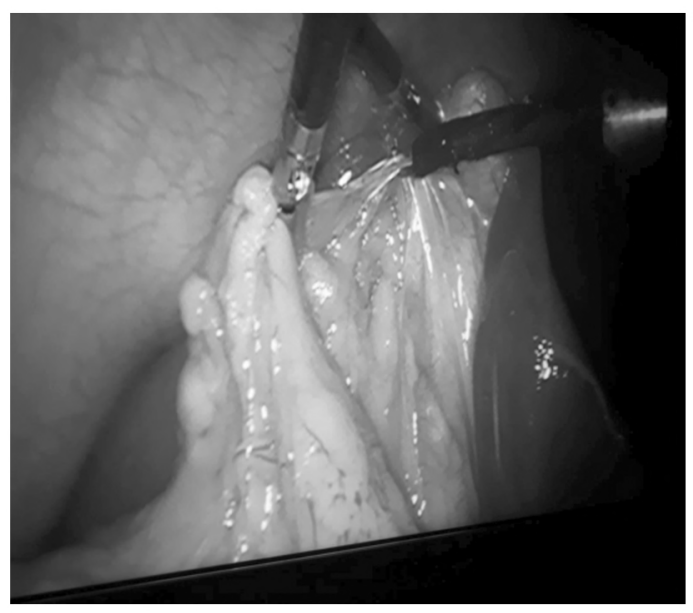

(A): Surrounding adhesions

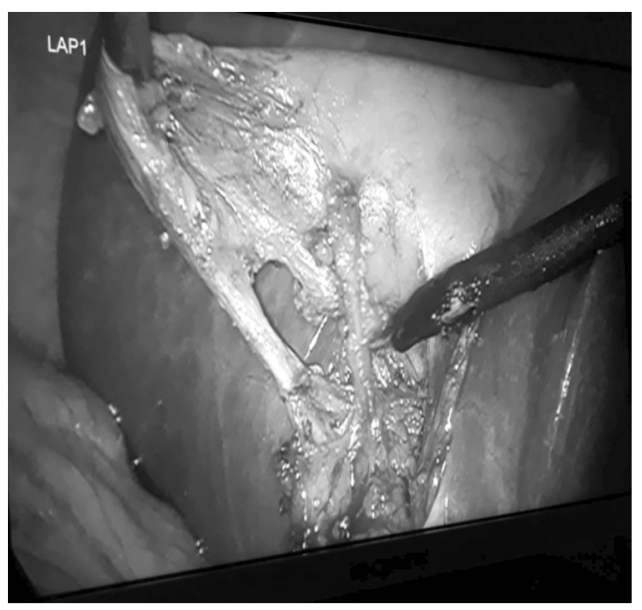

(B): After dissection of callot triangle.

Fig. (1): Case in moderate group undergone laparoscopic cholecystectomy. 


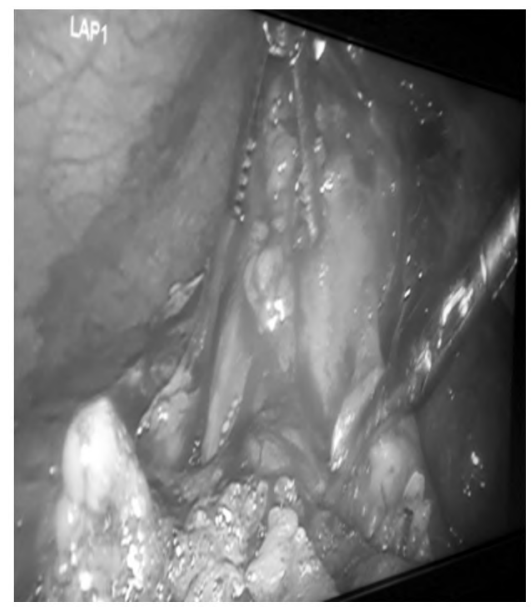

(A): Before conversion.

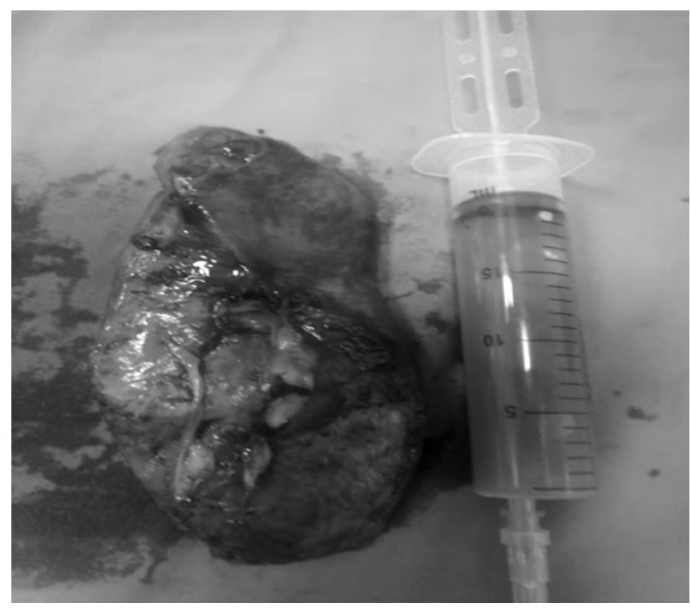

(B): After conversion.

Fig. (2): A case in mild group needed intraoperative conversion.

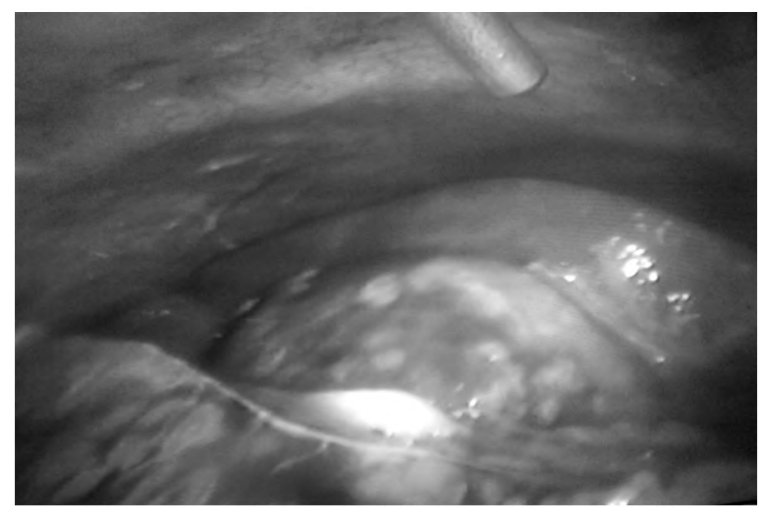

(A): Before conversion.

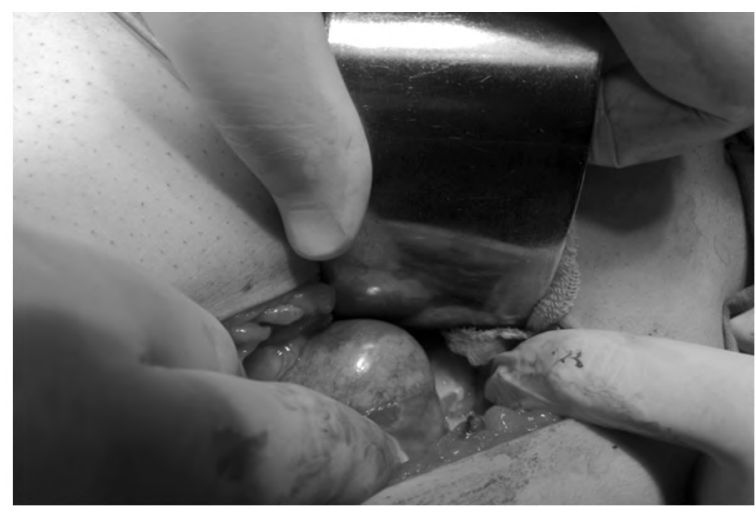

(B): After conversion.

Fig. (3): A case from moderate group needed intraoperative conversion.

\section{Discussion}

28 patients $(56 \%)$ presented with mild attack, 13 patients $(26 \%)$ with moderate attack while 9 patients $(18 \%)$ with severe attack. $93 \%$ of mild group, $77 \%$ of moderate group and $89 \%$ of severe group were diagnosed by only U.S. All patients in mild and moderate group undergone early laparoscopic cholecystecyomy. 2 patients $(7 \%)$ in mild group and 1 patient $(7.5 \%)$ in moderate group needed intraoperative conversion to open surgery. All patients in severe group undergone conservative management which was successful in 6 patients $(67.7 \%)$ and they undergone late laparoscopic cholecystectomy and none of them needed conversion to open surgery but conservative treatment failed in 3 patients $(33.3 \%), 2$ of them (22.2) undergone urgent open cholecystectomy and one of them (11.1\%) undergine urgent open cholecystostomy. There was intraoperative bleeding in the 3 patients (100\%) needed intra operative conversion from lap. To open which was statistically significant in comparison to only 5 patients (13.2\%) from patients completed the lap and not significant to $50 \%$ bleeding in open cholecystectomy group. There was no CBD injury or bowel injury in all groups. The median time of operation was longer in conversion group (85 minutes) in comparison to (47 minutes) in early lap group which is statistically significant but not significant to 80 minutes in open cholecystectomy group. During postoperative follow-up, $18.4 \%$ from early lap group presented with severe pain in comparison to $16.7 \%$ in late lap group $100 \%$ of open surgery. There was no post-operative bleeding, jaundice, evidence of bowel injury in all groups. One patient from the early lap group (2.6\%) and one patient in the open cholecystectomy group (50\%) presented with bile leak (about 150cc bile/day) which undergone conservative treatment and leak stopped after 4 days and did not need surgical. One patient from the conversion group $(66.7 \%)$ presented with wound 
infection which was statistically non-significant to open cholecystostomy group (100\%). Median time of hospital stay was 3 days in conversion group in comparison to 1 day in early lap group which was statistically significant. Median time of starting post-operative oral feeding was longer in conversion group (about 24 hours) in comparison to only 8 hours in early lap group which was statistically significant. Our study was statistically correlating with multiple studies in which conversion rate was seen to be $15.5 \%$ in early vs. $14.4 \%$ in delayed group $[\mathbf{1 0 , 1 1}]$ and also be seen in recently published study [12] where the conversion rate was $16 \%$ in early laparoscopic surgery with good accuracy according to intra operative and post-operative course.

\section{Conclusion and Recommendation:}

It's important to use Tokyo guidelines during diagnosis and treatment of acute calcular cholecystitis and to do early laparoscopic cholecystecyomy for patient with mild and moderate attack due to its high success rate and to give patient with severe attack agood conservative management for late laparoscopic surgery. We recommend more future studies on Tokyo guideliness especially severe group with large number of pateints, also recently published Tokyo guidelines 2018 needs to be studied with its new parameters in assessment and treatment of acute calcular cholecystitis.

\section{References}

1- STRASBERG S.M.: Clinical practice. Acute calculous cholecystitis. N. Engl. J. Med., 358: 2804-11, 2008.

2- CHAU C.H., TANG C.N., SIU W.T., HA J.P. and LI M.K.: Laparoscopic cholecystectomy versus open cholecystectomy in elderly patients with acute cholecystitis: Retrospective study. Hong Kong Med. J., 8: 394-9, 2006.

3- JOHANSSON M., THUNE A., BLOMQVIST A., NELVIN L. and LUNDELL L.: Management of acute cholecystitis in the laparoscopic era: Results of a prospective, randomized clinical trial. J. Gastrointest. Surg., 7: 642-5, 2003.

4- SCHREINEMAKERS J.M., MEYER Z., VAN DER SCHELLING G.P., CROLLA R.M. and RIJKEN A.M.: Complications after laparoscopic cholecystectomy: A video evaluation study of whether the critical view of safety was reached. World Journal of Surgery, 39: 1798803,2015

5- FARQUHARSON, MARGARET, JAMES HOLLINGSHEAD and BRENDAN MORAN: Farquharsons Textbook of operative general surgery. CRC Press, USA, 2014.

6- YAMASHITA Y., TAKADA T., KAWARADA Y., NIMU RA Y., HIROTA M., MIURA F., et al.: Surgical treatment of patients with acute cholecystitis: Tokyo Guidelines. J. Hepatobiliary Pancreat. Surg., 14: 91-7, 2007.

7- YOKOE M., TAKADA T., MAYUMI T., YOSHIDA M., HASEGAWA H., NORIMIZU S., et al.: Accuracy of the Tokyo Guidelines for the diagnosis of acute cholangitis and cholecystitis taking into consideration the clinical practice pattern in Japan. J. Hepatobiliary Pancreat. Sci. 18: 250-7, 2011.

8- MASAMICHI Y., TADAHIRO T., STEVEN M.S. JOSEPH S.S., TOSHIHIKO M., HARUMI G., et al.: New diagnostic criteria and severity assessment of acute cholecystitis in revised Tokyo guidelines. J. Hepatobiliary Pancreat. Sci., 19: 578-85, 2012.

9- KOHJI O., KENJI S., TADAHIRO T., STEVEN M.S., HORACIO J.A., ITARU E., et al.: Tokyo Guidelines 2018: Flowchart for the management of acute cholecystitis. J. Hepatobiliary Pancreat. Sci., 25: 55-72, 2018.

10- RATI A., K.C. SOOD and BHUPENDER A.: Evaluation of Early versus Delayed Laparoscopic Cholecystectomy in Acute Cholecystitis. Surgery Research and Practice, Article ID 349801, 7 pages 2015.

11- PETER C.A., HILDEGARD C. and DIRK W.: Does the Tokyo guidelines predict the extent of gallbladder inflammation in patients with acute cholecystitis? A single center retrospective analysis. B.M.C. Gastroenterology, 15: 142, 2015 .

12- SADAF K., ZAHID I. and AFSAR A.B.: Early Versus Delayed Laparoscopic Cholecystectomy For Acute Cholecystitis. J. Ayub. Med. Coll. Abbottabad., 29: 570-3, 2017. 


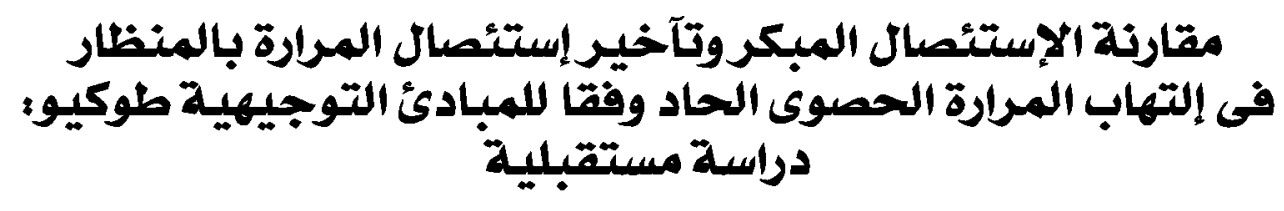

الهدف: دراسة دور المبادئ التوجيهية طوكيو (با ـץ) في تصديد درجة الإلتهاب الصصوى الحاد للمراره وتصديد الطريقة المناسبة للعلاج والوقت المناسب لإستئصالها بالمنظار سواء كان مبكرا آو في وقت متآخر.

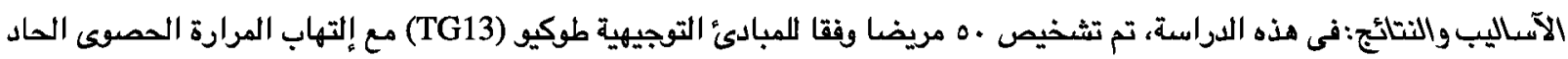

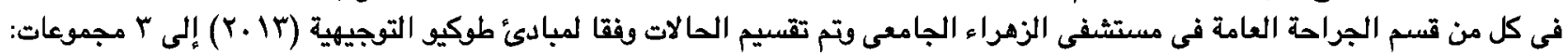

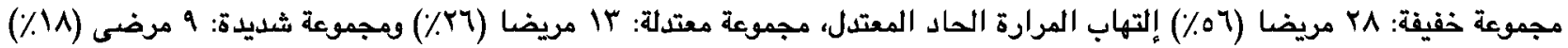

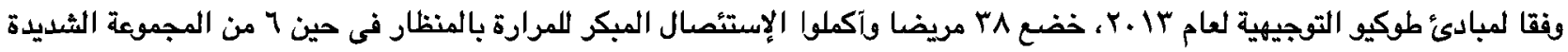

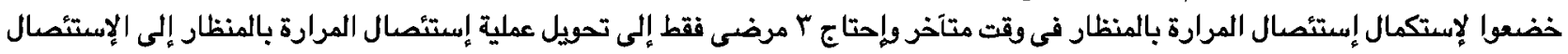
الجراحى بينما إحتاج ب مرضى آخرين لعملية الإستئصال الجراحى للمرارة من البداية بسبب فشل العلاج التحفظى.

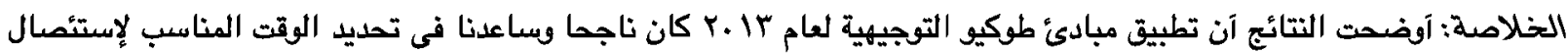

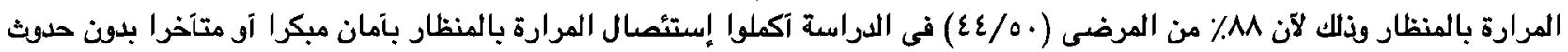

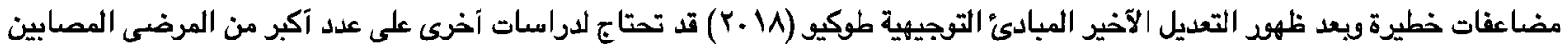
بإلتهاب المرارة الحصوى الحفاد. 